\title{
Original
}

\section{Effect of combination therapy with alogliptin and lansoprazole on glycemic control in patients with type 2 diabetes}

\author{
Kohzo Takebayashi ${ }^{1)}$, Shintaro Sakurai ${ }^{1)}$, Tatsuhiko Suzuki ${ }^{1)}$, Kenichiro Hori ${ }^{1)}$, Tomoko Terasawa ${ }^{1)}$, \\ Hiroshi Shuutou $^{4)}$ and Toshihiko Inukai ${ }^{1)}$ \\ 1) Department of Internal Medicine, Dokkyo Medical University Koshigaya Hospital, Koshigaya, Japan \\ 2) Higashiwashinomiya Hospital, Kuki, Japan \\ 3) Hamasaki Clinic, Kasukabe, Japan \\ 4) Iryouhoujinkenshinkai-minamikoshigayakenshinkai Clinic, Koshigaya, Japan
} Rika Naruse $^{1)}$, Kenji Hara ${ }^{1)}$, Mariko Suetsugu ${ }^{1)}$, Takafumi Tsuchiya ${ }^{1)}$, Hiromi Aoki ${ }^{2)}$, Takashi Hamasaki ${ }^{3)}$,

\begin{abstract}
The main purpose of the current study was to investigate the effect of a combination of alogliptin [a dipeptydil peptidase (DPP)-4 inhibitor] and lansoprazole [a proton pump inhibitor (PPI)] compared with alogliptin mono-therapy on glycemic control in patients with type 2 diabetes. This study was a multicenter randomized open-label study. One hundred type 2 diabetic patients were randomly assigned to either the alogliptin with lansoprazole group or the alogliptin monotherapy group. After 3 months of treatment, the changes in hemoglobin (Hb)Alc, fasting plasma glucose (FPG), serum gastrin, homeostasis model assessment (HOMA)- $\beta$, and HOMA-insulin resistance (IR) were evaluated. A significant decrease in HbA1c and FPG, and a significant increase in HOMA- $\beta$ were observed in both groups (all with $P<0.0001$ ). However, there were no significant differences in changes in HbA1c, FPG, or HOMA- $\beta$ before and after therapy between the combination and alogliptin mono-therapy group $(P=0.2945, P=0.1901, P=0.3042$, respectively). There was a significant elevation of serum gastrin in the combination group compared with the alogliptin mono-therapy group $(P$ $=0.0004)$. This study showed that, although combination therapy with alogliptin and lansoprazole more effectively elevated serum gastrin levels compared with alogliptin mono-therapy, the effect of the combination therapy on glycemic control was equal to that of alogliptin mono-therapy during a 3-month study period.
\end{abstract}

Key words: Gastrin, DPP4 inhibitor, Type 2 diabetes

GASTRIN is a hormone secreted from $\mathrm{G}$ cells in the gastric pyloric gland that regulates gastric acid secretion in the parietal cells of the stomach. Gastrin also promotes $\beta$-cell neogenesis from pancreatic duct cells and increases islet mass in a rat-model with ligated pancreatic ducts [1]. In humans, Meier et al. recently reported a case showing increased pancreatic $\beta$-cell replication adjacent to gastrinomas, suggesting a direct effect of gastrin on pancreatic tissues [2]. Proton pump inhibitors (PPI), which are widely used clinically for the treatment of gastro-esophageal reflex diseases, gastritis due to excess stomach acid, and gastric

Submitted May 10, 2014; Accepted Jul. 16, 2014 as EJ14-0208 Released online in J-STAGE as advance publication Sep. 2, 2014

Correspondence to: Kohzo Takebayashi, M.D., Department of Internal Medicine, Dokkyo Medical University Koshigaya Hospital, 2-1-50, Minami-Koshigaya, Koshigaya 343-8555, Japan.

E-mail: takeb@gmail.plala.or.jp ulcers, can indirectly elevate serum gastrin levels [3-8]. Interestingly, in animal models of type 2 diabetes, it is reported that PPI treatment improves glycemic control [9], probably via its possible effect in increasing serum gastrin levels. Furthermore, in human retrospective or cross-sectional studies, an association between administration of PPI and better glycemic control in patients with type 2 diabetes was reported [10-12]. However, two recent prospective randomized double blind placebo-controlled studies using PPI in a small number of patients with type 2 diabetes showed conflicting results of its effect on glycemic control $[13,14]$.

Importantly, recent evidence suggests the potentially beneficial effect of combination therapy of various hormones rather than single hormone therapy [15]. In fact, combination therapy with glucagon-like peptide-1 (GLP-1) and gastrin more effectively improves hyperglycemia than single therapy by each hormone in non- 
obese diabetic (NOD) mice (animal model of type 1 diabetes) [16]. This result is also supported in the same animal model by combination therapy with dipeptidyl peptidase (DPP)-4 inhibitors, which block degradation of GLP-1 by DPP4 resulting in the elevation of serum active GLP-1 levels [17], and PPI. Although these studies were performed in type 1 diabetic animal models, a very recent study showed that combination therapy with exendin-4 (a GLP-1 receptor agonist) and omeprazole (a PPI) more effectively improved glycemic control than single therapy for these drugs in $\mathrm{db} /$ $\mathrm{db}$ mice (an animal model of obesity and type 2 diabetes) [18]. Furthermore, in db/db mice, a GLP-1-gastrin dual agonist has showed a more sustained gluco-regulatory effect accompanied with significant increase of $\beta$-cell mass in pancreatic tissue than liraglutide (a GLP-1 receptor agonist) monotherapy [19]. Taken together, these studies suggest the possibility that, also in type 2 diabetes patients, combination therapy with DPP4-inhibitors and PPI may provide a more beneficial effect for glycemic control than mono-therapy with DPP4 inhibitors. However, there is no evidence showing the combination-effect of DPP4-inhibitors and PPI for glycemic control in patients with type 2 diabetes. Based on these findings, we investigated the combination effect of alogliptin (a DPP4 inhibitor) and lansoprazole (a PPI) on glycemic control, compared with the effect of alogliptin alone in patients with type 2 diabetes in this multicenter, randomized study. We hypothesized that combination therapy with alogliptin and lansoprazole would provide better glycemic control than alogliptin mono-therapy.

\section{Patients and Methods}

\section{Patients}

The sample size was determined based on the effect of alogliptin on $\mathrm{HbAlc}$ levels because we predicted that combination-therapy can reduce $\mathrm{HbAlc}$ levels at least to the same degree as that observed with alogliptin mono-therapy. Based on the previous study performed in Japan [20], we hypothesized that alogliptin can achieve an $0.8 \%$ reduction of $\mathrm{HbAlc}$, and based on our clinical experience in our hospital, a mean \pm standard deviation (SD) of $\mathrm{HbA} 1 \mathrm{c}$ at baseline was sought to be $8.0 \pm 1.0 \%$. With a power of $90 \%$ and $\alpha$ of 0.05 two tailed, a sample size of 36 per group would be required.

This study was a multicenter randomized open-label study but it was not a double-blind study, because the use of a placebo and a double-blind design are not usually permitted as a post-marketing clinical study in Japan. 100 patients were recruited from December 2012 to August 2013 in 5 institutions ( 2 hospital including Dokkyo Medical University Koshigaya Hospital and 3 medical clinics) for this study named APPLE; study of combination effect of AlogliPtin and lansoPrazoLE on glycemic control in patients with type 2 diabetes. This study was registered at UMIN 0000009445. After enrollment, patients were assigned to two groups [alogliptin alone $(\mathrm{n}=50)$ and alogliptin + lansoprazole $(\mathrm{n}=50)]$, by a central computer system based on $\mathrm{HbA1c}, \mathrm{BMI}$, gender, and age.

Key inclusion criteria were 1) patients aged 20 or over, 2) patients diagnosed as type 2 diabetes according to the Japan Diabetic Society Criteria [21], 3) outpatient status, 4) patients with $6.5 \%$ and greater $\mathrm{HbA} 1 \mathrm{c}$ levels, and with $0.5 \%$ or less variation of $\mathrm{HbA} 1 \mathrm{c}$ in 1 month prior to the study, 5) patients who did not receive DPP4 inhibitors during 1 month prior to the study, 6) patients in whom type and dose of all drugs including anti-diabetic ones was not changed during 1 month prior to the study, and 7) patients giving consent in writing for participation for this study. Key exclusion criteria were 1) patients with severe ketosis, diabetic coma, or type 1 diabetes, 2) patients with severe infectious disease, within 1 month after surgery, or having a severe traumatic injury, 3) patients with allergy to either alogliptin or lansoprazole, 4) patients under atazanavir-treatment, 5) patients treated with PPIs of all types or $\mathrm{H}_{2}$ blockers of all types, 6) patients treated with insulin, and 7) patients otherwise judged as unacceptable for participation in this study by our medical doctor.

Clinical and laboratory tests showed no evidence of liver dysfunction or autoimmune disease in any patients. No patients showed serum creatinine levels exceeding $1.1 \mathrm{mg} / \mathrm{dL}$. Patients visited the hospital and had blood and urine tests basically monthly. Seven patients in the alogliptin alone arm dropped out of the study. One patient discontinued the drug due to epigastric pain, and 1 patient was released due to suspicion of pancreatic cancer. Four patients were found to have poor compliance with the drugs. One patient was found to have had $\mathrm{HbA} 1 \mathrm{c}<6.5 \%$ on enrollment. Four patients dropped from the study in the combination group with alogliptin and lansoprazole. One patient withdrew due to a mild cerebral infarction, and 1 patient withdrew because of implantation of a pacemaker. One patient noticed occasional hypoglycemic 
Table 1 Clinical characteristics of the patients treated with alogliptin alone and alogliptin and lansoprazole

\begin{tabular}{|c|c|c|c|}
\hline & Alogliptin & Alogliptin + lansoprazole & $P$ \\
\hline No. (male/female) & $43(23 / 20)$ & $46(24 / 22)$ & - \\
\hline Age (year) & $65.8 \pm 12.4$ & $64.8 \pm 9.2$ & 0.6554 \\
\hline BMI $\left(\mathrm{kg} / \mathrm{m}^{2}\right)$ & $24.9 \pm 4.3$ & $25.4 \pm 4.1$ & 0.6412 \\
\hline FPG (mg/dL) & $153.6 \pm 34.4$ & $159.7 \pm 34.5$ & 0.4065 \\
\hline HbAlc (\%) & $7.7 \pm 0.5$ & $7.6 \pm 0.6$ & 0.5205 \\
\hline \multicolumn{4}{|l|}{ Diabetic therapy } \\
\hline \multicolumn{4}{|l|}{ SU } \\
\hline$(\mathrm{S} 1 / \mathrm{S} 2 / \mathrm{S} 3 / \mathrm{S} 4 / \mathrm{S} 5 / \mathrm{S} 6 / \mathrm{S} 7 / \mathrm{S} 8)$ & $6 / 6 / 7 / 2 / 1 / 3 / 2 / 0$ & $8 / 7 / 9 / 0 / 1 / 1 / 2 / 1$ & - \\
\hline \multicolumn{4}{|l|}{ MET } \\
\hline (M1/M2/M3/M4) & $2 / 1 / 3 / 1$ & $3 / 0 / 1 / 1$ & - \\
\hline$\alpha \mathrm{GI}$ alone & 2 & 2 & - \\
\hline Pioglitazone alone & 1 & 1 & - \\
\hline \multicolumn{4}{|l|}{ Antihypertensive drugs } \\
\hline$(\mathrm{A} / \mathrm{C} / \mathrm{AC})$ & $3 / 2 / 10$ & $6 / 2 / 12$ & - \\
\hline Statins & 15 & 13 & - \\
\hline
\end{tabular}

Data are expressed as mean \pm standard deviation (SD), Comparison in variables between two groups were made by use of an unpaired $t$ test. $P: p$ value, $P<0.05$ are defined as statistical significance. BMI, body mass index; FPG, fasting plasma glucose; Diabetic therapy, the number of the patients with respective diabetic therapies; SU, sulfonylurea; MET, metformin; $\alpha$-GI, $\alpha$ glucosidase inhibitor; S1:SU alone, S2: SU and MET, S3: SU, MET and $\alpha$-GI, S4: SU, MET, $\alpha$-GI and pioglitazone, S5: SU, MET and pioglitazone, S6: SU and pioglitazone, S7: SU and $\alpha$-GI, S8: SU, pioglitazone and $\alpha$-GI, M1: MET alone, M2: MET and pioglitazone, M3: MET and $\alpha$-GI, M4: MET, pioglitazone and $\alpha$-GI. Antihypertensive drugs: the number of the patients with respective antihypertensive drugs, A: angiotensin-II receptor blocker (ARB), C: calcium channel blocker (CA), AC: ARB and CA

symptoms after starting the drugs. One patient was found to have poor compliance with the drugs. As a result, 43 patients in the alogliptin mono-therapy group and 46 in the combination group with alogliptin and lansoprazole completed the study.

The characteristics of the patients treated with alogliptin alone and with alogliptin and lansoprazole are shown in Table 1.

\section{Methods}

The use of lansoprazole is non-approved indication for the treatment of diabetes in Japan. Therefore lansoprazole was administrated to the patients without insurance treatment in Japan; we covered the related cost of lansoprazole administration instead of patients. There would be an ethical problem because of the non-approved use of this drug if the unexpected side effect occurred by long-term administration of this drug. Thus, we decided to choose the relatively short-term study period (3 months) although it appears to be more effective in longer term treatment as a year if the mechanism on possible glucose-lowering effect of PPI is based on the improvement of $\beta$-cell function. Another reason why we chose 3 months as study period was based on the results of the study in Singh et al. [13] in which PPI significantly decreased the HbA1c levels in 3 months study period.

Primary outcomes of this study for each group were $\mathrm{HbAlc}$ and fasting plasma glucose (FPG) levels 3 months after starting the study. Key secondary outcomes for each group were fasting serum gastrin and plasma insulin levels, HOMA-IR, HOMA- $\beta$, and body weight 3 months after starting the study. No change in drug administration was made for any patient during the 3 months after starting the study.

Blood and urine were basically collected in the outpatient department from 8:30 to 9:30 a.m. after overnight fasting for at least $10 \mathrm{hr}$. After the blood was collected, it was immediately placed into specific test tubes for different assays, and then rapidly centrifuged at 1,500 rpm for 5 minutes to separate the serum or plasma from the clot-containing blood cells. Except for samples for glucose, $\mathrm{HbAlc}$, and lipid measurements, the samples were stored frozen at $-70^{\circ} \mathrm{C}$ until analysis. At the time of sampling, the patients were weighed.

\section{Measurement of plasma glucose, hemoglobin ( $\mathrm{Hb}) \mathrm{A1c}$, and serum lipids}

Fasting plasma glucose (FPG) was evaluated immediately after blood collection using an automated glucose oxidase method (Glucose Auto Stat GA1160®; 
Arkray, Kyoto, Japan). HbAlc was also measured immediately after collection of blood in a test tube containing EDTA-2K using high-performance lipid chromatography (HPLC; Hi-Auto $\mathrm{A}_{1 \mathrm{C}}{ }^{\circledR}, \mathrm{HA} 8150 \AA$; Arkray). Only $\mathrm{HbAlc}$ is detected with this method and the normal range is $4.5 \%$ to $6.2 \%$ [NGSP: national glycohemoglobin standardization program]. Serum total cholesterol (TC), low-density lipoprotein cholesterol (LDL-C), high-density lipoprotein cholesterol (HDL-C), and serum triglyceride (TG) were measured using enzymatic assays. The Determiner L TC II ${ }^{\circledR}$ and Determiner L TG ${ }^{\circledR}$ reagents (Kyowa Medics, Tokyo, Japan) were used for measurements of TC and TG, respectively. HDL-C was measured directly by a method based on selective solubilization of different lipoproteins by proprietary detergents using Cholestest N HDL-C® (Daiichi Pure Chemicals, Tokyo, Japan). LDL-C was also measured directly by a homogenous method using Cholestest LDL $\AA$ (Daiichi Pure Chemicals), rather than indirectly using the Friedwald equation. Serum gastrin was measured by a radioimmunoassay (RIA)-PEG method using the Gastrin RIA kit II ${ }^{\circledR}$ (TFB, Tokyo, Japan). The normal value of fasting gastrin using this kit was less than $200 \mathrm{pg} / \mathrm{mL}$. Plasma insulin was measured by a chemiluminescent enzyme immunoassay (CLEIA) using the lumipulse Presto Insulin Kit ${ }^{\circledR}$ (Fujirebio, Tokyo, Japan)

Homeostasis model assessment-insulin resistance (HOMAIR), and Homeostasis model assessment $\beta$ (HOMA- $\beta$ )

HOMA-IR was used as an indicator of insulin resistance and was calculated as follows: HOMA-IR = FPG $(\mathrm{mg} / \mathrm{dL}) \times$ fasting immunoreactive insulin $(\mu \mathrm{U} /$ $\mathrm{mL}) / 405$. HOMA- $\beta$ was used as an indicator of insulin secretion activity and was calculated as follows: HOMA- $\beta=360 \times$ fasting immunoreactive insulin $(\mu \mathrm{U} /$ $\mathrm{mL}$ )/fasting plasma glucose ( $\mathrm{mg} / \mathrm{dL})-63$.

\section{Ethical considerations}

All subjects gave informed consent for inclusion in the study. The study was approved by the Local Ethics Committee in our hospital and was performed according to the guidelines of the Declaration of Helsinki.

\section{Statistical methods}

The two time points for each parameter for an individual were compared using a paired $t$-test, except those for gastrin, for which a Wilcoxon signed rank test was used as a non-parametric test due to its skewed distributions. Comparisons between the two groups were made using an unpaired t-test for normally distributed data (confirmed by a $\chi^{2}$ test); a Student $t$-test or a Welch $t$-test was chosen based on the homogeneity of variance calculated by an F-test. Comparisons of various markers in alogliptin- and those in alogloptin with lansoprazole-treated patients for changes from baseline were assessed using an analysis of variance (ANCOVA) model with treatment as fixed effects and the corresponding baseline value as a covariate. For $\mathrm{HbAlc}$ and FPG, least square (LS) mean difference were estimated for the comparison of alogliptin and alogliptin with lansoprazole. Comparison of the proportion of patients who achieved $\mathrm{HbAlc}$ equal to or less than $6.5 \%$ and $7.0 \%$ in two groups was analyzed by the $\chi^{2}$ test. In the ANCOVA and single regression analysis, values of gastrin were $\log _{10}$-transformed. A $P$ value of less than 0.05 was accepted as indicating statistical significance (two-sided).

\section{Results}

Changes in various variables at baseline and at 3 months in patient-groups treated with either alogliptin alone or alogliptin and lansoprazole are presented in Table 2. A significant decrease was obtained in HbA1c and in FPG in both groups. However, there was no significant difference in the change in $\mathrm{HbAlc}$ and in FPG before and after therapy based on analysis using ANCOVA between the two groups; LS mean changes with standard error (SE) of HbAlc at 1, 2 and 3 months were respectively $0.567 \pm 0.158,0.927 \pm 0.185$ and 0.997 $\pm 0.086 \%$ in the alogliptin alone group, and those were respectively $0.651 \pm 0.158,1.000 \pm 0.185$ and $0.839 \pm$ $0.083 \%$ in the combination group. LS mean change with SE of FPG at 1, 2 and 3 months were respectively $16.0 \pm 4.3,15.0 \pm 4.1,26.8 \pm 3.4 \mathrm{mg} / \mathrm{dL}$ in the alogliptin group, and those were respectively $9.3 \pm 4.5,15.3 \pm 4.2$, $21.6 \pm 3.2 \mathrm{mg} / \mathrm{dL}$ in the combination group (Fig. 1A, B). In subgroups of patients with sulfonylurea ( \pm other antidiabetic drugs), with metformin ( \pm other anti-diabetic drugs), and without anti-diabetic drugs at baseline in both treatment groups, there were no significant difference in the change in $\mathrm{HbAlc}$ and in FPG at baseline and at 3 months after therapy between two treatment groups ( $\mathrm{P}=0.0945,0.2978,0.2146$ in $\mathrm{HbAl}$ c, and $P=0.4361$, 0.4060, 0.3888 in FPG, respectively).

The proportion of patients who achieved an $\mathrm{HbAlc}$ equal to or less than $6.5 \%$ and $7.0 \%$ was respectively $35 \%$ and $84 \%$ in the alogliptin alone group, and $43 \%$ and $72 \%$ in the combination group (no significant difference between the two groups). For serum gastrin 
Table 2 Changes in various variables at baseline and 3 months after therapy

\begin{tabular}{|c|c|c|c|c|c|c|c|}
\hline & \multicolumn{3}{|c|}{ Alogliptin } & \multicolumn{3}{|c|}{ Alogliptin + lansoprazole } & \multirow[b]{2}{*}{$P^{*}$} \\
\hline & Baseline & 3 months & $P$ (Difference: $95 \% \mathrm{CI})$ & Baseline & 3 months & $P$ (Difference: $95 \% \mathrm{CI})$ & \\
\hline FPG (mg/dL) & $153.6 \pm 34.4$ & $128.5 \pm 26.6$ & $0.0001(17.0-33.2)^{*}$ & $152.0 \pm 35.6$ & $127.3 \pm 27.4$ & $<0.0001(16.7-32.7)^{*}$ & 0.1901 \\
\hline $\mathrm{HbAlc}(\%)$ & $7.7 \pm 0.5$ & $6.7 \pm 0.5$ & $<0.0001(0.8-1.2)^{*}$ & $7.6 \pm 0.6$ & $6.8 \pm 0.7$ & $<0.0001(0.6-1.0)^{*}$ & 0.2945 \\
\hline $\mathrm{TC}(\mathrm{mg} / \mathrm{dL})$ & $184.4 \pm 29.5$ & $178.7 \pm 28.9$ & $0.1705(-2.6-, 13.8)$ & $194.9 \pm 32.1$ & $181.0 \pm 36.1$ & $0.0083(3.9-24.0)^{*}$ & 0.3439 \\
\hline $\mathrm{TG}(\mathrm{mg} / \mathrm{dL})$ & $120.3 \pm 129.1$ & $110.7 \pm 102.5$ & $0.1757(-4.4,23.5)$ & $123.4 \pm 68.5$ & $141.3 \pm 158.8$ & $0.3042(-52.6,16.8)$ & 0.1532 \\
\hline HDL-C (mg/dL) & $58.2 \pm 14.9$ & $56.9 \pm 13.7$ & $0.3154(-1.3,4.0)$ & $53.4 \pm 14.5$ & $49.3 \pm 14.0$ & $0.0001(2.2-6.1)^{*}$ & $0.0218^{*}$ \\
\hline LDL-C (mg/dL) & $105.0 \pm 24.8$ & $99.4 \pm 25.6$ & $0.0580(-0.2,11.3)$ & $108.7 \pm 30.6$ & $100.2 \pm 26.1$ & $0.0110(2.0-14.9)^{*}$ & 0.7325 \\
\hline $\mathrm{SBP}(\mathrm{mm} \mathrm{Hg})$ & $131.7 \pm 10.8$ & $127.9 \pm 12.9$ & $0.0253(0.5,7.1)^{*}$ & $132.9 \pm 10.6$ & $128.3 \pm 11.1$ & $0.0422(0.2-9.2)^{*}$ & 0.9223 \\
\hline $\mathrm{DBP}(\mathrm{mm} \mathrm{Hg})$ & $74.5 \pm 9.9$ & $74.3 \pm 10.0$ & $0.8688(-2.6,3.1)$ & $75.9 \pm 9.6$ & $74.3 \pm 10.6$ & $0.3691(-2.0,5.2)$ & 0.6779 \\
\hline BW (kg) & $64.4 \pm 15.0$ & $64.0 \pm 15.0$ & $0.0398(0.02,0.7)^{*}$ & 66.2 & $65.6 \pm 11.6$ & $0.0369(0.04,1.2)^{*}$ & 0.4427 \\
\hline Insulin $(\mu \mathrm{U} / \mathrm{mL})$ & $7.7 \pm 5.7$ & $7.4 \pm 6.4$ & $0.7776(-1.6,2.1)$ & $9.8 \pm 8.2$ & $10.0 \pm 8.6$ & $0.9065(-2.3,-2.0)$ & 0.4635 \\
\hline Gastrin (pg/mL) & $110(68,190)$ & $120(77.5,265)$ & $0.00085^{*}$ & $97(70,110)$ & $180(110,400)$ & $<0.0001^{*}$ & $0.0004^{*}$ \\
\hline HOMA-IR & $3.0 \pm 2.2$ & $2.4 \pm 2.3$ & $0.0944(-0.1,1.2)$ & $4.0 \pm 3.7$ & $3.6 \pm 3.5$ & $0.4643(-06,1.3)$ & 0.7781 \\
\hline НОМА- $\beta$ & $35.3 \pm 34.8$ & $48.1 \pm 44.9$ & $0.0171(-23.1,-2.4)^{*}$ & $37.6 \pm 33.4$ & $52.9 \pm 55.6$ & $0.0242(-28.4,-2.1)^{*}$ & 0.3042 \\
\hline
\end{tabular}

$P: p$ value for change before and after therapy by paired $t$ test. $P^{*}: p$ value for comparisons in alogliptin and in alogliptin with lansoprazole group for changes from baseline assessing using analysis of variance (ANCOVA) model with treatment as fixed effects and corresponding baseline value as covariate. $P<0.05$ are defined as statistically significant $\left(^{*}\right)$. CI, confidence interval

Data are expressed as means \pm SD except for gastrin which are expressed as medians with interquartile ranges $\left(25^{\text {th }}\right.$ and $75^{\text {th }}$ percentile). FPG, fasting plasma glucose; HbA1c, hemoglobin A1c; TC, total cholesterol; TG, triglyceride; HDL-C, high-density lipoprotein cholesterol; LDL, low-density lipoprotein cholesterol; SBP, systolic blood pressure; DBP, diastolic blood pressure; BW, body weight; HOMA-IR, Homeostasis model assessment insulin resistance; HOMA- $\beta$, Homeostasis model assessment $\beta$

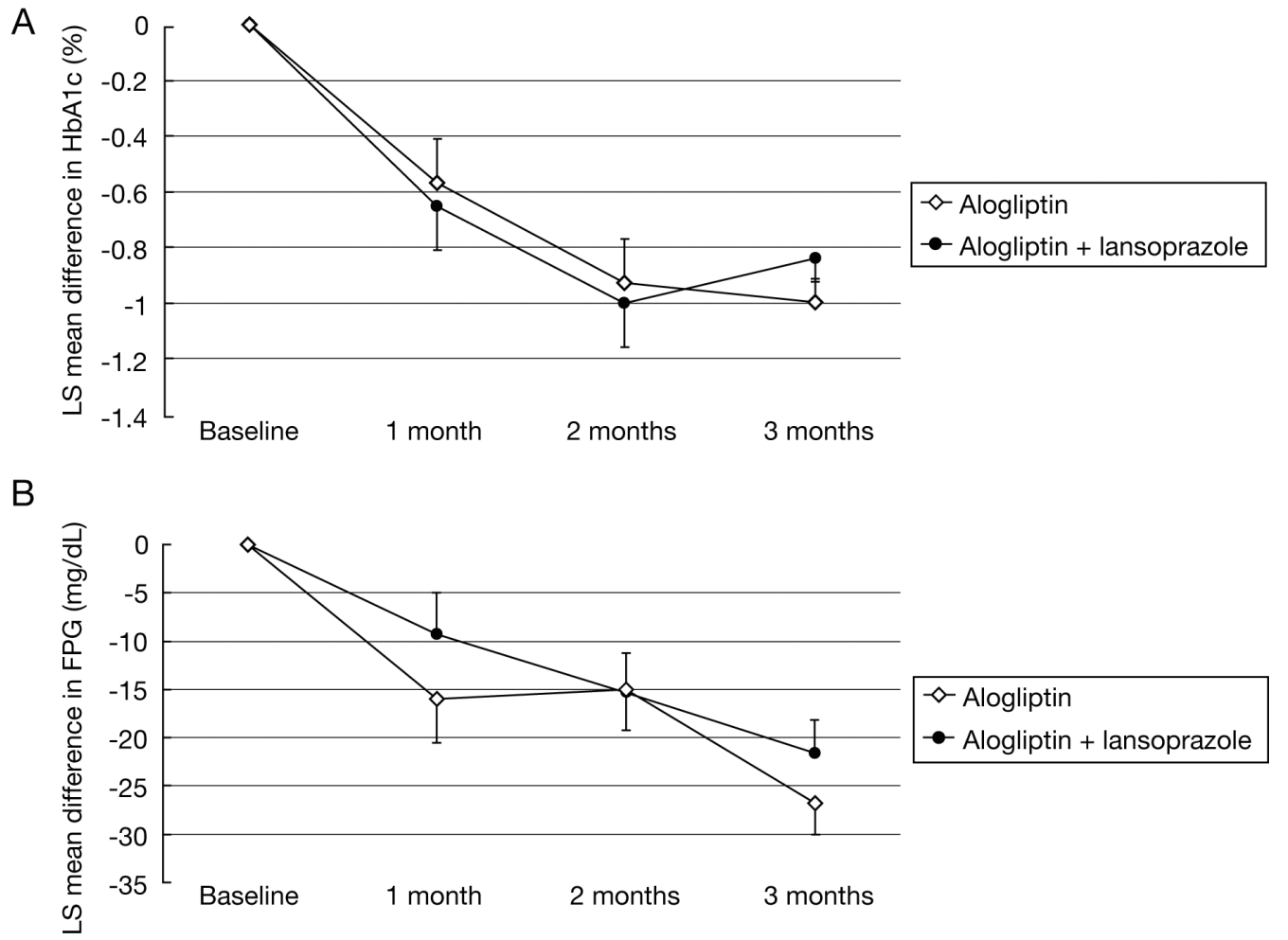

Fig.1 LS mean difference in HbAlc (A) and FPG (B) before and after 3 months in one group treated with alogliptin and in another group treated with alogliptin and lansoprazole in patients with type 2 diabetes 

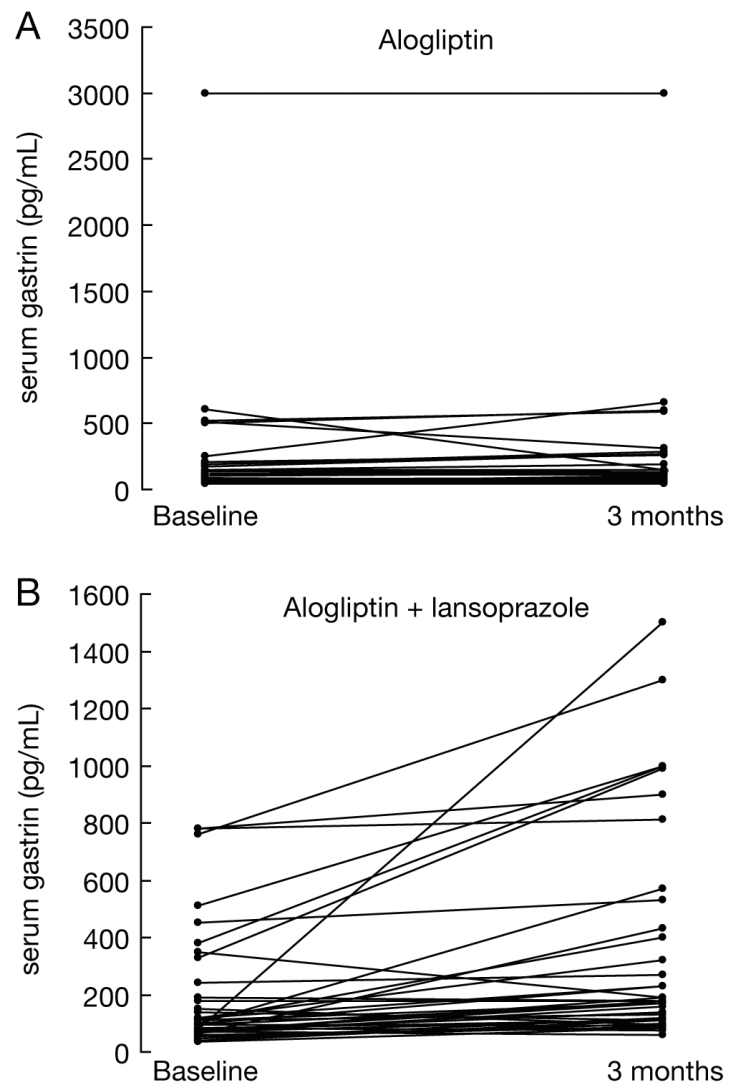

Fig. 2 Change in serum gastrin before and after 3 months in one group treated with alogliptin (A) and in another group treated with alogliptin and lansoprazole (B) in patients with type 2 diabetes

levels, there was significant elevation before and after therapy in both groups, however, the difference in gastrin $\left(\log _{10}\right.$-transformed) before and after therapy as analyzed using ANCOVA showed a significant elevation of gastrin in the combination group when compared with those in the alogliptin alone group (Fig. 2A, B).

A significant decrease in both SBP and BW and a significant elevation in HOMA- $\beta$ by treatment was obtained in both groups, and a significant decrease in TC, LDL-C and HDL-C was found in the combination group.

There was no correlation between $\log _{10}$-transformed gastrin and $\mathrm{HbA1c}$, FPG, insulin, HOMA-IR, or HOMA- $\beta$ in baseline in both groups.

The correlation between the difference in $\log _{10^{-}}$ transformed gastrin and those in various markers before and after therapy in two groups is presented in Table 3.

There were no apparent side effects in both groups in this study except for hypoglycemic symptom recognized in 1 patient in combination group.
Table 3 Correlation of difference before and after therapy in log-transformed gastrin with those in various markers

\begin{tabular}{lcc}
\hline Correlation with $\Delta$ gastrin & & \\
\hline Alogliptin group & $\mathrm{R}$ & $P$ \\
& 0.3592 & $0.0369^{*}$ \\
$\Delta$ insulin & 0.1621 & 0.3521 \\
$\Delta$ FPG & 0.0128 & 0.9419 \\
$\Delta$ HbA1c & 0.4226 & $0.0179^{*}$ \\
$\Delta$ HOMA-IR & 0.3631 & $0.0447^{*}$
\end{tabular}

Alogliptin + lansoprazole group

$\begin{array}{lcc} & \mathrm{R} & P \\ \Delta \text { insulin } & 0.2622 & 0.0925 \\ \Delta \text { FPG } & 0.1818 & 0.2254 \\ \Delta \text { HbA1c } & 0.1508 & 0.3467 \\ \Delta \text { HOMA-IR } & 0.2984 & 0.0650 \\ \Delta \text { HOMA- } \beta & 0.1659 & 0.3128\end{array}$

Total patients (total of both groups)

$\begin{array}{lcc} & \mathrm{R} & P \\ \Delta \text { insulin } & 0.2668 & 0.0207^{*} \\ \Delta \text { FPG } & 0.1554 & 0.1801 \\ \Delta \text { HbAlc } & 0.1443 & 0.2136 \\ \Delta \text { HOMA-IR } & 0.3139 & 0.0081^{*} \\ \Delta \text { HOMA- } \beta & 0.2193 & 0.0694\end{array}$

$\Delta$, the difference in each marker before and after therapy, FPG, fasting plasma glucose; HbAlc, hemoglobin A1c; HOMA-IR, Homeostasis model assessment insulin resistance; HOMA- $\beta$, Homeostasis model assessment $\beta$

\section{Discussion}

In the current study, we investigated the effect of combination therapy with alogliptin (a DPP4 inhibitor) and lansoprazole (a PPI) on glycemic control in patients with type 2 diabetes and compared the findings with that of alogliptin mono-therapy. Contrary to our expectation, the effects on glycemic control of the two therapies were equivalent. The results in this study do not support those found in previous studies in an animal model of type 2 diabetes with either combination-therapy of GLP-1 receptor agonist and PPI [18], or with GLP-1-gastrin dual agonist [19]. It is difficult to explain the reason for the unexpected result in this study. However, the observational period of the retrospective study on glycemic control with PPI monotherapy in patients with type 2 diabetes, which showed positive results on glycemic control, was longer than 1 year [10]. One recent prospective study in patients with type 2 diabetes treated with PPI mono-therapy for 
3 months using pantoprazole significantly decreased the HbA1c levels [13], while in another study using esomeprazole for the same observation period [14], there was no effect. Because the possible effect of gastrin on glycemic control appears to be at least partially dependent on the effect of gastrin (or gastrin with GLP-1) [12] for replication of pancreatic $\beta$ cells which would probably take relatively long term, a longer observation-period of more than a year may be needed to find the effect on glycemic control of single PPI or combination therapy of PPI with DPP4.

Interestingly, although there was no correlation in the present study between serum gastrin levels and plasma insulin levels, HOMA- $\beta$, or HOMA-IR in baseline in both groups, a significantly positive correlation was observed between differences before and after therapy in serum gastrin levels and in plasma insulin levels, HOMA- $\beta$ or HOMA-IR in the alogliptin monotherapy group. Therefore, speculatively, the change in serum gastrin levels might basically correlate with the change in insulin secretion activity as evaluated by HOMA- $\beta$ or that in insulin resistance as evaluated by HOMA-IR under the condition in which change in gastrin levels is not so large (i.e., within physiological variation range). However, even under this condition, gastrin does not probably fully affect glycemic control, since gastrin might be associated with both insulin secretion and insulin resistance. Notably, these correlations were attenuated in the combination therapy group. Therefore, excess elevation of gastrin by drugs, such as PPI, appears not always to be associated with an increase in insulin secretion. This may also be based on the relatively short-term (3 months) observation in this study.

In a previous study using pantoprazole [13], the dose of the drug was approximately twice that used clinically used for gastro-esophageal reflux disease. The dose of lansoprazole in this study $(15 \mathrm{mg} /$ day $)$ was what is usually used in treatment for gastilitis or gastric ulcer. However, in the current study, the degree of elevation of serum gastrin levels in combination therapy was approximately twice, and was higher than that (1.5 hold) in the study using pantoprazole. Therefore, the dose of lansoprazole in this study appears to have been basically effective for the elevation for serum gastrin. However, treatment longer than 3 months would be expected to further increase serum gastrin levels [22, 23]. It may be possible that, especially in combination therapy with DPP4 inhibitors and PPI unlike PPI mono-therapy, more highly-elevated serum gastrin levels are needed to show the benefit on glycemic control exceeding that of DPP4 inhibitor mono-therapy itself. Therefore, also from this aspect, it may be interesting to observe the combinational effect with DPP4 inhibitors and PPI for a longer observation period.

We investigated the combination effect of a DPP4inhibitor and PPI. In animal studies in which a synergistic effect on glycemic control was obtained [18, 19], a GLP-1 receptor agonist with PPI or gastrin-GLP-1 dual agonist instead of DPP4-inhibitors with PPI was used. It is well known that the elevation of serum GLP-1 levels with a DPP4-inhibitor is a milder treatment compared with that of a GLP-1 receptor agonist. Therefore, even if the degree of elevation of serum gastrin by PPI is high, it may be possible that a GLP-1 receptor agonist with PPI will be more synergistic for glycemic control than DPP4-inhibitors with PPI. Accordingly, it would be interesting in the future to investigate the effect of a combination therapy with PPI using a GLP-1 receptor agonist on glycemic control.

Recently, Wallace JL et al. reported that PPI can induce dysbiosis [24]. It is known that dysbiosis is connected with metabolic syndrome. Therefore, speculatively, PPI may worsen glycemic control in this aspect, and therefore may be able to cancel its potential beneficial effect on glycemic control based on the effect gastrin. This may also be one of the reasons why the effects on glycemic control of the two therapies were equivalent.

In this study, significant reduction in TC, LDL-C, and HDL-C was found in combination therapy. It is difficult to clearly explain the reason why these results were obtained. However, it is unlike that lansoprazole influenced the decrease of these lipids levels, because it is reported that PPI therapy for 3 months significantly increased (but not decreased) TC and LDL-C levels with no change of HDL-C in patients with type 2 diabetes [25]. On the other hand, it is reported that alogliptin can reduce LDL-C levels [26-28], although these levels did not change in some studies [29, 30]. Recently, Ayaori et al. reported that alogliptin significantly reduced TC, LDL-C, and HDL-C (but not TG), and that it significantly deceased HDL-C, even when compared with sitagliptin [28]. Thus, we speculate that decrease of TC, LDL-C, and HDL-C which were observed in this study was probably associated with the effect of alogliptin, although the precise mechanism is unknown. In fact, also in alogliptin group, the tendency of decrease of these lipids was found; this 
change may have been significant if the study was performed in larger number of patients.

Apart from the relative short term-observation, this study has limitations. This study was not double-blinded using a placebo. In addition, it is known that diabetes occasionally occurs with gastroesophageal reflux disease (GERD). We could not investigate the proportion of patients with GERD in this study. Because PPI largely improves GERD clinical symptoms, it may be possible that the appetite of the patients with GERD was improved, resulting in potentially worsening glycemic control. This may also explain partially the lack of a synergy effect with PPI and DPP4-inhibitor on glycemic control in this study. Finally, we missed measuring plasma GLP-1 and gastric inhibitory polypeptide (GIP) levels in this study. It may have been important to investigate the degrees of elevation of plasma GLP-1 and GIP levels by these therapies. We admit that this is also one of the limitations of this study.

In conclusions, in the current study, we showed that the effect on glycemic control of combination therapy with alogliptin and lansoprazole is equal to that of alogliptin mono-therapy in a 3-month study. Longer observation for the effect of combination therapy by DDP4-inhibitor and PPI, and a study using GLP-1 receptor agonist instead of DPP4-inhibitor with PPI would be warranted.

\section{Disclosure Summary}

The authors have nothing to disclose. There is no conflict of interest that could be perceived as prejudicing the impartiality of the research reported.

\section{References}

1. Rooman I, Lardon J, Bouwens L (2002) Gastrin stimulates $\beta$-cell neogenesis and increases islet mass from transdifferentiated but not from normal exocrine pancreas tissue. Diabetes 51: 686-690.

2. Meier JJ, Butler AE, Galasso R, Rizza RA, Butler PC (2006) Increased islet beta cell replication adjacent to intrapancreatic gastrinomas in humans. Diabetologia 49: 2689-2696.

3. Sheen E, Triadafilopoulos G (2011) Adverse effects of long-term proton pump inhibitor therapy. Dig Dis Sci 56: 931-950.

4. Ligumsky M, Lysy J, Siguencia G, Friedlander Y (2001) Effect of long-term, continuous versus alternate-day omeprazole therapy on serum gastrin in patients treated for reflux esophagitis. J Clin Gastroenterol 33: 32-35.

5. $\mathrm{Hu}$ YM, Mei Q, Xu XH, Hu XP, Hu NZ, Xu JM (2006) Pharmacodynamic and kinetic effect of rabeprazole on serum gastrin level in relation to CYP2C19 polymorphism in Chinese Hans. World $J$ Gastroenterol 12: 4750-4753.

6. Cadiot G, Vissuzanic C, Pospai D, Ruszniewski P, Potet F, Mignon M (1995) Effect of prolonged treatment with proton pump inhibitors on serum gastrin levels and the fundus mucosa. Preliminary results. Gastroenterol Clin Biol 19: 811-817 (In French).

7. Koop H, Klein M, Arnold R (1990) Serum gastrin levels during long-term omeprazole treatment. Aliment Phamacol Ther 4: 131-138.

8. Sanders SW, Tolman KG, Greski PA, Jennings DE, Hoyos PA, Page JG (1992) The effects of lansoprazole, a new $\mathrm{H}+, \mathrm{K}(+)$-ATPase inhibitor, on gastric $\mathrm{pH}$ and serum gastrin. Aliment Phamacol Ther 6: 359-372.
9. Bödvarsdóttir TB, Hove KD, Gotfredsen CF, Pridal L, Vaag A, et al. (2010) Treatment with a proton pump inhibitor improves glycaemic control in Psammomys obesus, a model of type 2 diabetes. Diabetologia 53: 2220-2223.

10. Hove KD, Færch K, Bödvarsdóttir TB, Karlsen AE, Petersen JS, Vaag A (2010) Treatment with a proton pump inhibitor improves glycaemic control in type 2 diabetic patients-a retrospective analysis. Diabetes Res Clin Pract 90: e72-e74.

11. Crouch MA, Mefford IN, Wade EU (2012) Proton pump inhibitor therapy associated with lower glycosylated hemoglobin levels in type 2 diabetes. $J$ Am Board Fam Med 25: 50-54.

12. Boj-Carceller D, Bocos-Terraz P, Moreno-Vernis M, Sanz-Paris A, Trincado-Aznar P, Albero-Gamboa R (2011) Are proton pump inhibitors a new antidiabetic drug? A cross sectional study. World J Diabetes 2: 217220.

13. Singh PK, Hota D, Dutta P, Sachdeva N, Chakrabarti A, et al. (2012) Pantoprazole improves glycemic control in type 2 diabetes: a randomized, double-blind, placebo-controlled trial. J Clin Endocrinol Metab 97: E2105-E2108.

14. Hove KD, Brøns C, Færch K, Lund SS, Petersen JS, et al. (2013) Effects of 12 weeks' treatment with a proton pump inhibitor on insulin secretion, glucose metabolism and markers of cardiovascular risk in patients with type 2 diabetes: a randomized double-blind prospective placebo-controlled study. Diabetologia 56: 22-30.

15. Sadry SA, Drucker DJ (2013) Emerging combinational hormone therapies for the treatment of obesity and 
T2DM. Nat Rev Endocrinol 9: 425-433.

16. Suarez-Pinzon WL, Power RF, Yan Y, Wasserfall C, Atkinson M, Rabinovitch A (2008) Combination therapy with glucagon-like peptide-1 and gastrin restores normoglycemia in diabetic NOD mice. Diabetes 57: 3281-3288.

17. Suarez-Pinzon WL, Cembrowski GS, Rabinovitch A (2009) Combination therapy with a dipeptidyl peptidase-4 inhibitor and a proton pump inhibitor restores normoglycaemia in non-obese diabetic mice. Diabetologia 52: 1680-1682.

18. Patel V, Joharapurkar A, Gandhi T, Patel K, Dhanesha $\mathrm{N}$, et al. (2013) Omeprazole improves the anti-obesity and antidiabetic effects of exendin-4 in $\mathrm{db} / \mathrm{db}$ mice. $J$ Diabetes 5: 163-71.

19. Fosgerau K, Jessen L, Lind Tolborg J, Østerlund T, Schæffer Larsen K, et al. (2013) The novel GLP-1gastrin dual agonist, ZP3022, increases $\beta$-cell mass and prevents diabetes in $\mathrm{db} / \mathrm{db}$ mice. Diabetes Obes Metab 15: 62-71.

20. Seino Y, Fujita T, Hiroi S, Hirayama M, Kaku K (2011) Efficacy and safety of alogliptin in Japanese patients with type 2 diabetes mellitus: a randomized, double blind, dose-ranging comparison with placebo, followed by a long-term extension study. Curr Med Res Opin 27: 1781-1792.

21. Treatment guide for diabetes edited by Japan Diabetes Society 2007 (Bunkodo Co., Ltd, Tokyo, Japan).

22. Singh P, Indaram A, Greenberg R, Visvalingam V, Bank K (2000) Long term omeprazole therapy for reflux esophagitis: follow-up in serum gastrin levels, EC cell hyperplasia. World J Gastroentrol 6: 789-792.

23. Brunner G, Athmann C, Schneider A (2012) Long-term open-label trial: safety and efficacy of continous maintenance treatment with pantprazole for up to 15 years in severe acid-peptic disease. Aliment Pharmacol Ther 36: 37-47.

24. Wallace JL, Syer S, Denou E, de Palma G, Vong L, et al. (2011) Proton pump inhibitors exacerbate NSAIDinduced small intestinal injury by inducing dysbiosis. Gastroenterology 141: 1314-1322.

25. Hove KD, Brøns C, Færch K, Lund SS, Petersen JS, et al. (2013) Effects of 12 weeks' treatment with a proton pump inhibitor on insulin secretion, glucose metabolism and markers of cardiovascular risk in patients with type 2 diabetes: a randomized double-blind prospective placebo-controlled study. Diabetologia 56: 22-30.

26. Kaku K, Itayasu T, Hiroi S, Hiryama M, Seino Y (2011) Efficacy and safety of alogliptin added to pioglitazone in Japanese patients with type 2 diabetes: a randomized, double-blind, placebo-controlled trial with an openlabel long-term extension study. Diabetes Obes Metab 13: $1028-1035$.

27. Seino Y, Fujita T, Hiroi S, Hirayama M, Kaku K (2011) Alogliptin plus voglibose in Japanese patients with type 2 diabetes: a randomized, double blind, placebo-controlled trial with an open-label, long-term extension . Curr Med Res Opin 27: Supple 3: 21-29.

28. Ayaori M, Iwakami N, Uto-Kondo H, Sato H, Sasaki M, et al. (2013) Dipeptidyl peptidase-4 inhibitors attenuate endothelial fuction as evaluated by flow-mediated vasodilatation in type 2 diabetic patients. J Am Heart Assoc 2: e003277.

29. Kaku K, Itayasu I, Hiroi S, Hirayama M, Seino Y (2011) Efficacy and safety of alogliptin added to pioglitazone in Japanese patients with type 2 diabetes: a randomized, double-blind, placebo-controlled trial with an openlabel long-term extension study. Diabetes Obes Metab 13: $1028-1035$.

30. Seino Y, Miyata Y, Hiroi S, Hirayama M, Kaku K (2012) Efficacy and safety of alogliptin added to metformin in Japanese patients with type 2 diabetes: a randomized, double-blind, placebo-controlled trial with an open-label, long-term extension study. Diabetes Obes Metab 14: 927-936. 